\author{
이유자돈에 있어 대두유, 건조팜유분말과 Monoglyceride의 첨가가 \\ 성장 및 혈청 지질변화에 미치는 영향 \\ 민병준 · 권오석 · 이원백 · 홍종욱 · 김인호 \\ 단국대학교 동물자원과학과
}

\title{
The Effect of Soybean Oil, Dried Palm Oil Powder and Monoglyceride Supplementation on Growth Performance and Serum Lipid Changes in Weaned Pigs
}

\author{
B. J. Min, O. S. Kwon, W. B. Lee, J. W. Hong and I. H. Kim \\ Department of Animal Resource \& Science, Dankook University
}

\begin{abstract}
This experiment was conducted to determine the Effect of soybean oil, dried palm oil powder and monoglyceride supplementation on growth performance and serum lipid changes in weaned pigs. One hundred twenty five cross-bred $\operatorname{pigs}((\mathrm{Y} \times \mathrm{L}) \times \mathrm{D}, 6.00 \pm 0.79 \mathrm{~kg}$ average initial $\mathrm{BW})$ were used in a $21 \mathrm{~d}$ growth trial. Dietary treatments included SOY(containing 5\% soybean oil), PALM(containing 5.5\% dried palm oil powder) and SOPM0, 12.5 and 25(containing 2.5\% soybean oil and 2.7\% dried palm oil powder containing $0 \%, 12.5 \%$ and $25.0 \%$ monoglyceride, respectively). For the whole period, ADFI was increased in dried palm oil powder containing monoglyceride and PALM treatments compared with SOY and SOPM0 treatment $(\mathrm{P}<0.05)$. ADG and $\mathrm{G} / \mathrm{F}$ were not affected by treatments. Digestibility of fat was higher $(\mathrm{P}<0.05)$ for pigs fed SOY diet than fed other diets. SOPM diets containing monoglyceride showed increased fat digestibility compared with PALM $\operatorname{diet}(\mathrm{P}<0.05)$. SOPM12.5 and SOPM25 treatments were no difference with SOY treatment. However, there were no significant differences in digestibilities of $\mathrm{DM}, \mathrm{N}$ and $\mathrm{DE}(\mathrm{P}>0.05)$. Backfat thicknesses were not significantly different among treatments. Pigs fed SOY diet was decreased in serum total cholesterol, HDL-cholesterol, total lipid and was increased in free fatty acid than those fed other diet. Also, triglyceride concentration in serum was increased in PALM treatment compared with SOPM treatment $(\mathrm{P}=0.06)$. In conclusion, feeding soybean oil in weaned pigs showed higher fat digestibility and lower cholesterol and triglyceride concentration in serum than feeding only dried palm oil powder. Also, pigs fed monoglyceride were improved fat digestibility compared with those fed dried palm oil powder only.

(Key words : Dry palm oil powder, Monoglyceride, Growth performance, Serum lipid, Weaned pigs)
\end{abstract}

\section{I. 서 론}

양돈 사료 내 지방의 첨가는 사료 섭취량을 감소시키지 않는 범위 내에서 사료의 에너지 증 가를 위해 필수적으로 사용되어 왔다. 특히, 이
유자돈에 있어 지방의 첨가는 증체량, 사료효율 을 증가시키며(Crampton과 Ness, 1954; Lawrence 와 Maxwell, 1983), 지방산 소화율을 개선시키 는 것(Frobish 등, 1970)으로 알려져 있다. 그러 나, 그 효과는 첨가되어지는 지방원의 종류, 첨

Corresponding author : I. H. Kim, Department of Animal Resource \& Science, Dankook University. \#29 Anseodong, Cheonan, Choognam, 330-714, Korea

Tel : +82-41-550-3652, Fax : +82-41-550-3604, E-mail : inhokim@dankook.ac.kr 
가량, 첨가방법 또는 자돈의 연령에 따라서 차 이가 다르게 나타난다(NRC, 1998). Li 등(1990) 은 이유자돈 사료 내 대두유와 야자유의 혼합 급여가 대두유 또는 야자유의 단일급여와 비교 하여 성장율 및 소장 융모 길이를 증가시켰다 고 보고하였으며, Lawrence 등(1980)은 이유자 돈에 $8 \%$ 이상의 지방첨가는 증체량을 감소시 킨다고 보고하였다.

Palm oil은 야자열매의 일종인 Elaesis guineensis 의 과육을 압착시 생산되는 지방으로서 동남아 시아, 서부 또는 중부 아프리카에서 식용으로 많이 이용되어지는 지방원이며, 다른 일반적인 식물성 지방원과는 달리 포화지방산의 함량이 많으며, vitamin A 및 $\mathrm{E}$ 를 다량 함유하고 있다 (Gapor 등, 1989; Clerc, 1992). 가축사료 내 palm oil 첨가의 효과는 육계에 있어 성장율 개선 (Panja 등, 1995) 및 이유자돈에 있어 성장율, 사 료섭취량 증가(Fanimo 와 Fashina-bombata, 1998) 의 효과가 있다고 보고되고 있으나, 이와 관련 한 연구의 수가 적으며, 그 효과 또한 일정하 지 않다.

본 실험에 사용된 palm oil은 그 성상을 분말 형태로 제조하여 $12.5 \%$ 또는 $25 \%$ 의 monoglyceride 를 포함한 것으로서 monoglyceride 형태로의 지 방은 소장 내에서 직접 흡수, 이용되어진다고 알려져 있다(Mattson과 Beck, 1956).

따라서, 본 연구는 이유자돈에 있어 대두유, 건조팜유 분말과 monoglyceride의 첨가가 성장 및 혈청 내 콜레스테롤, 중성지방 및 유리지방 산의 변화에 미치는 영향을 구명하기 위하여 실시되었다.

\section{․․재료 및 방법}

\section{1. 시험동물 및 시험설계}

개시시 체중 $6.00 \pm 0.79 \mathrm{~kg}$ 인 3원 교잡종 [(Yorkshire $\times$ Landrace $) \times$ Duroc] 자돈 125두를 공 시하여 21일간 사양시험을 실시하였다. 시험설 계는 기초사료 내 일반대두유 $5 \%$ 를 함유한 처 리구(SOY), 건조분말팜유 $5.5 \%$ 를 함유한 처리 구(PALM), 일반대두유 $2.5 \%$ 와 $0 \%, 12.5 \%, 25 \%$
의 monoglyceride를 각각 첨가한 건조팜유분말 $2.7 \%$ 를 함유한 처리구(SOPM0, SOPM12.5, SOPM25) 의 5 개 처리를 하여 처리당 5 반복, 반복당 5 마 리씩 완전임의 배치하였다.

\section{2. 시험사료 및 사양관리}

시험에 사용된 사료의 조성은 Table 1에 나 타내었으며, 본 시험에 사용된 monoglyceride가 함유된 건조팜유분말은 지방원료와 glycerol 및 $\mathrm{NaOH}$ 혼합에 의해 제조된 monoglyceride를 palm oil에 첨가하여 교반한 후, 스프레이 쿨러 를 통하여 분말화 시켜 사용하였다. 시험사료 는 가루형태로 자유채식토록 하였고 물은 자동 급이기를 이용하여 자유로이 마실 수 있도록 하였다. 체중 및 사료섭취량은 시험개시시, 7일 령과 시험종료시에 측정하여 일당증체량, 일당 사료섭취량, 사료효율을 계산하였다. 또한, 영 양소 소화율을 측정하기 위하여 표시물로 산화 크롬 $\left(\mathrm{Cr}_{2} \mathrm{O}_{3}\right)$ 을 사료 내에 $0.2 \%$ 첨가하여 사양시 험 개시 후, 20 일령에 분을 채취하여 분석에 이용하였다.

\section{3. 조사항목}

혈청생화학적 검사를 위하여 시험종료시 처 리당 10마리씩 경정맥에서 vacuum tube(Becton Dickinson Vacutainer Systems, Franklin Lakes, NJ, USA)를 이용하여 혈액을 $5 \mathrm{ml}$ 채취한 후, $4^{\circ} \mathrm{C}$ 에서 $2,000 \times \mathrm{g}$ 로 30 분간 원심분리하여 혈청 을 분석에 이용하였다. 분리된 혈청은 R208 영동 Cholestero - R시약(영동제약, 한국)과 triglyceride 검사시약(BOEHRINGER MANNHEIM, Germany) 에 반응시켜 자동생화학 분석기(HITACHI 747, HITACHI, Japan)를 통해 total-cholesterol과 triglyceride를 각각 측정하였으며, HDL-cholesterol 은 자동분석기(HITACHI 7150, HITACHI, Japan) 를 통하여 측정하였다. 혈청 내 Total lipid의 함량은 혈청 $0.1 \mu \ell$ 에 황산 $1.5 \mathrm{ml}$ 을 혼합하여 10 분간 가열 후, phosphor-vanillin용액 $6 \mathrm{ml}$ 과 반응시켜 $540 \mathrm{~nm}$ 의 atomic absorption Spectrophotometer(HITACHI Photometer 4010, Japan)에 
Table 1. Diet composition(as-fed basis)

\begin{tabular}{|c|c|c|c|}
\hline \multirow{2}{*}{ Ingredient } & $\mathrm{SOY}^{1)}$ & PALM $^{1)}$ & $\mathrm{SOPM}^{1)}$ \\
\hline & \multicolumn{3}{|c|}{$\%$} \\
\hline Expanded corn & 40.14 & 39.64 & 39.94 \\
\hline Dried whey & 21.00 & 21.00 & 21.00 \\
\hline Soybean meal & 19.73 & 19.73 & 19.73 \\
\hline Fish meal & 5.00 & 5.00 & 5.00 \\
\hline Soybean oil & 5.00 & - & 2.50 \\
\hline Dried palm oil powder & - & 5.50 & 2.70 \\
\hline Spray-dried animal plasma & 3.00 & 3.00 & 3.00 \\
\hline Sugar & 3.00 & 3.00 & 3.00 \\
\hline Calcium carbonate & 0.66 & 0.66 & 0.66 \\
\hline Acidifier & 0.50 & 0.50 & 0.50 \\
\hline Phosphate defluorinated & 0.44 & 0.44 & 0.44 \\
\hline L-Lysine $\cdot \mathrm{HCl}$ & 0.31 & 0.31 & 0.31 \\
\hline Zinc oxide & 0.30 & 0.30 & 0.30 \\
\hline Colistin & 0.20 & 0.20 & 0.20 \\
\hline DL-Methionine & 0.12 & 0.12 & 0.12 \\
\hline Choline chloride & 0.11 & 0.11 & 0.11 \\
\hline Trace mineral premix ${ }^{2)}$ & 0.10 & 0.10 & 0.10 \\
\hline Vitamin premix ${ }^{3)}$ & 0.10 & 0.10 & 0.10 \\
\hline Neomycine (11\%) & 0.10 & 0.10 & 0.10 \\
\hline Efrrotomycin (1\%) & 0.08 & 0.08 & 0.08 \\
\hline Oxytetracycline (20\%) & 0.06 & 0.06 & 0.06 \\
\hline $\mathrm{CuSO}_{4}$ & 0.04 & 0.04 & 0.04 \\
\hline Antioxidant(Ethoxyquin 66.6\%) & 0.01 & 0.01 & 0.01 \\
\hline \multicolumn{4}{|l|}{ Chemical composition $^{4)}$} \\
\hline $\mathrm{ME}, \mathrm{kcal} / \mathrm{kg}$ & 3,450 & 3,453 & 3,447 \\
\hline Crude protein, \% & 20.00 & 19.95 & 19.98 \\
\hline Digestible lysine, \% & 1.34 & 1.34 & 1.34 \\
\hline Digestible methionine + cystine, \% & 0.76 & 0.76 & 0.76 \\
\hline Calcium, \% & 0.90 & 0.90 & 0.90 \\
\hline Phosphorus, \% & 0.62 & 0.62 & 0.62 \\
\hline
\end{tabular}

1) Abbreviated SOY, 5\% soybean oil; PALM, 5\% dried palm oil powder; SOPM, 2.5\% soybean oil and 2.5\% dried palm oil powder.

2) Provided per kg diet : $140 \mathrm{mg}$ of $\mathrm{Cu} ; 179 \mathrm{mg}$ of $\mathrm{Zn} ; 12.5 \mathrm{mg}$ of $\mathrm{Mn} ; 0.5 \mathrm{mg}$ of I; $0.25 \mathrm{mg}$ of Co and $0.4 \mathrm{mg}$ of Se.

3) Provided per kg diet : 20,000IU of vitamin A; 4,000IU of vitamin $\mathrm{D}_{3}$; $80 \mathrm{IU}$ of vitamin $\mathrm{E} ; 16 \mathrm{mg}$ of vitamin $\mathrm{K}_{3}$; $4 \mathrm{mg}$ of thiamine; $20 \mathrm{mg}$ of riboflavin; $6 \mathrm{mg}$ of pyridoxine; $0.08 \mathrm{mg}$ of vitamin $\mathrm{B}_{12} ; 120 \mathrm{mg}$ of niacin; $50 \mathrm{mg}$ of Ca-pantothenate; $2 \mathrm{mg}$ of folic acid and $0.08 \mathrm{mg}$ of biotin.

4) Calculated value.

서 측정하였다. 혈청 내 free fatty acid의 함량

은 SICDIA NEFAZYME시약(영연화학, 한국)을 이용하여 자동분석기(HITACHI 7150, HITACHI, Japan)를 통하여 측정하였다.
등지방 두께 측정은 시험종료시에 digital backfat indicator(LEAN-MEATER; Renco, Minneapolis, $\mathrm{MN}$ )를 이용하여 첫번째 및 마지막 늑골과 마 지막 요추부위에서 측정하였다. 


\section{4. 화하분석 및 통계처리}

사료의 일반성분과 표시물로 혼합된 $\mathrm{Cr}$ 은 AOAC (1995) 방법에 의해 분석하였다.

모든 자료는 SAS (1996)의 General Linear Model procedure를 이용하여 분산분석을 실시하 였고, 처리간 평균의 차이는 Duncan's multiple range test(Duncan, 1955)을 이용하여 검정하였 다.

\section{III. 결과 및 고찰}

시험에 사용된 지방원료에 대한 지방산 조성 을 Table 2에 나타내었다. 시험에 사용된 dried palm oil powder의 경우, 다른 식물성 유지, 특 히, soybean oil과는 대조적으로 포화지방산이 전체 지방산 조성 중 $61.00 \%$ 를 차지하였으며, 이 중 palmitic acid(C16:0)와 stearic acid(C18:0) 가 $59.5 \%$ 였으며, oleic acid(C18:1)는 $35.50 \%$ 를 차지하였다. NRC(1998)에 의하면, palm oil의 지 방산 중 palmitic acid와 oleic acid가 각각 43.5\%

Table 2. Fatty acid composition of experimental fat sources

\begin{tabular}{lccc}
\hline Fatty acids, \% & & ${\text { Soybean } \text { oil }^{\text {a) }}}^{\text {C }} \begin{array}{c}\text { Dried palm } \\
\text { oil powder }\end{array}$ \\
\hline \hline Lauric & C12:0 & - & - \\
Myristic & C14:0 & 0.10 & 1.50 \\
Pentadecanoic & C15:0 & - & - \\
Palmitic & C16:0 & 10.30 & 47.30 \\
Palmitoleic & C16:1 & 0.20 & - \\
Magaric & C17:0 & - & - \\
Stearic & C18:0 & 3.80 & 12.20 \\
Oleic & C18:1 & 22.80 & 35.50 \\
Linoleic & C18:2 & 51.00 & 3.50 \\
Linolenic & C18:3 & 6.80 & - \\
Arachidic & C20:0 & - & - \\
Total SFA & & 15.10 & 61.00 \\
Total USFA & & 84.90 & 39.00 \\
U:S ratio & & 5.64 & 0.64 \\
\hline
\end{tabular}

a) Adapted from NRC(1998).
와 $36.6 \%$ 인 것으로 조사되었으며, $\operatorname{Jin}(1997)$ 의 시험에서도 palmitic acid와 oleic acid가 각각 $44.4 \%$ 와 $39.3 \%$ 으로 분석되어 본 시험에 사용된 dried palm oil powder와 유사한 결과를 나타내 었다.

이유자돈사료내 건조팜유분말이 성장에 미치 는 영향을 Table 3에 나타내었다. 일당증체량은 0 7일, 7 21일 및 0 21일간의 전 기간동안 처 리구간 차이가 없었다. 일당사료섭취량에 있어 서, 0 7일 동안은 SOPM25 구가 SOY 및 SOPM0 구보다 높았으나 $(\mathrm{P}<0.05), \mathrm{SOPM} 12.5$ 구와는 차 이가 없었으며 $(\mathrm{P}>0.05), \mathrm{SOY}$ 구는 다른 처리구 와 비교하여 섭취량이 낮았다 $(\mathrm{P}<0.05)$. 7 21일 에는 PALM과 SOPM12.5 구가 SOY 및 SOPM0 구보다 높아 0 21일간의 전체 사양시험기간동 안 PALM, SOPM12.5 및 SOPM25 구가 SOY 및 SOPM0 구보다 높게 나타났다 $(\mathrm{P}<0.05)$. 사료 효율에 있어서는 처리구간 차이를 보이지 않았 다(P>0.05). 식물성 유지 중 코코넛 유와 팜유 는 다른 식물성 유지와는 다르게 포화지방산을 주로 함유하고 있는 대표적인 유지이다. Cera 등(1989)은 이유자돈에 있어 코코넛 유의 급여 는 성장율 및 섭취량에 있어 다른 동물성 유지 와 혼합된 유지와 비교하여 높게 평가되었다고 보고하였으며, $\mathrm{Li}$ 등(1990)은 대두유와 코코넛 유의 혼합급여가 대두유와 비교하여 이유자돈 의 성장율과 사료섭취량을 향상시킨다고 보고 하였다. 본 실험에 있어 증체량은 통계적인 차 이는 보이지 않았으나, 대두유와 비교하여 건 조팜유분말와 대두유 혼합급여구에서 증가하는 경향을 보였으며, 사료섭취량에 있어서는 유의 적으로 증가하여 선행된 시험들과 유사한 결과 를 나타내었다. 그러나, Jones 등(1992)은 이유자 돈에 있어 tallow와 대두유 또는 monoglyceride의 혼합급여가 대두유의 단일급여과 비교하여 0 35일간의 사료섭취량에 영향을 미치지 못한 다고 보고하여 본 시험과 상이한 결과를 나타 내었다.

Table 4에는 건조팜유분말이 이유자돈의 소 화율에 미치는 영향을 나타내었다. 지방소화율 에 있어서 SOY 구가 가장 높았으며 $(\mathrm{P}<0.05)$, monoglyceride를 함유한 SOPM 구는 PALM 구 
Table 3. Effect of dried palm oil powder on growth performance in weaned pigs ${ }^{\perp}$

\begin{tabular}{|c|c|c|c|c|c|c|}
\hline \multirow{2}{*}{ Item } & \multirow{2}{*}{$\mathrm{SOY}^{2)}$} & \multirow{2}{*}{ PALM $^{2)}$} & \multicolumn{3}{|c|}{ SOPM $^{2)}$} & \multirow{2}{*}{$\mathrm{SE}^{3)}$} \\
\hline & & & 0 & 12.5 & 25 & \\
\hline \multicolumn{7}{|l|}{ 0 7 days } \\
\hline ADG, g & 174 & 182 & 186 & 191 & 195 & 20 \\
\hline ADFI, $g^{c}$ & $270^{\mathrm{b}}$ & $293^{\mathrm{ab}}$ & $276^{\mathrm{b}}$ & $287^{\mathrm{ab}}$ & $309^{\mathrm{a}}$ & 10 \\
\hline Gain/Feed & 0.644 & 0.621 & 0.674 & 0.666 & 0.631 & 57 \\
\hline \multicolumn{7}{|l|}{ 7 21 days } \\
\hline ADG, g & 310 & 322 & 318 & 333 & 324 & 19 \\
\hline ADFI, $\mathrm{g}^{\mathrm{cd}}$ & $535^{\mathrm{b}}$ & $571^{\mathrm{a}}$ & $531^{\mathrm{b}}$ & $572^{\mathrm{a}}$ & $554^{\mathrm{ab}}$ & 8 \\
\hline Gain/Feed & 0.579 & 0.564 & 0.599 & 0.582 & 0.585 & 31 \\
\hline \multicolumn{7}{|l|}{ 0 21 days } \\
\hline ADG, g & 266 & 277 & 267 & 280 & 279 & 18 \\
\hline ADFI, $\mathrm{g}^{\mathrm{cd}}$ & $405^{\mathrm{b}}$ & $440^{\mathrm{a}}$ & $399^{\mathrm{b}}$ & $435^{\mathrm{a}}$ & $432^{\mathrm{a}}$ & 9 \\
\hline Gain/Feed & 0.657 & 0.630 & 0.669 & 0.644 & 0.646 & 42 \\
\hline
\end{tabular}

1) One hundred twenty five pigs with an average initial body weight of $6.00 \pm 0.79 \mathrm{~kg}(\mathrm{SD})$.

2) Abbreviated SOY, 5\% soybean oil; PALM, 5.5\% dried palm oil powder; SOPM, $2.5 \%$ soybean oil and $2.7 \%$ dried palm oil powder included $0 \%, 12.5 \%$ and $25.0 \%$ monoglyceride.

3) Pooled standard error.

${ }^{a b}$ Means in the same row with different superscripts differ $(\mathrm{P}<0.05)$.

${ }^{c}$ Significant differences between SOY and others $(\mathrm{P}<0.05)$.

${ }^{\mathrm{d}}$ Significant differences between SOY and SOPM $(\mathrm{P}<0.1)$.

Table 4. Effect of dried palm oil powder on nutrient digestibility in weaned pigs ${ }^{1)}$

\begin{tabular}{|c|c|c|c|c|c|c|}
\hline \multirow{2}{*}{ Item, \% } & \multirow{2}{*}{$\mathrm{SOY}^{2)}$} & \multirow{2}{*}{ PALM $^{2)}$} & \multicolumn{3}{|c|}{$\mathrm{SOPM}^{2)}$} & \multirow{2}{*}{$\mathrm{SE}^{3)}$} \\
\hline & & & 0 & 12.5 & 25 & \\
\hline \multicolumn{7}{|l|}{ Day 20} \\
\hline $\mathrm{DM}$ & 87.19 & 86.68 & 86.30 & 85.99 & 86.45 & 0.91 \\
\hline $\mathrm{N}$ & 82.16 & 81.29 & 82.50 & 82.57 & 82.43 & 1.29 \\
\hline $\mathrm{Fat}^{\mathrm{cde}^{2}}$ & $80.92^{\mathrm{a}}$ & $71.55^{\mathrm{b}}$ & $76.14^{\mathrm{ab}}$ & $76.73^{\mathrm{a}}$ & $77.39^{\mathrm{a}}$ & 1.56 \\
\hline $\mathrm{DE}$ & 86.37 & 85.46 & 85.42 & 84.73 & 85.83 & 0.95 \\
\hline
\end{tabular}

1) Fecal samples were taken from fifteen pigs per treatment.

2) Abbreviated SOY, 5\% soybean oil; PALM, 5.5\% dried palm oil powder; SOPM, 2.5\% soybean oil and $2.7 \%$ dried palm oil powder included $0 \%, 12.5 \%$ and $25.0 \%$ monoglyceride.

3) Pooled standard error.

ab Means in the same row with different superscripts differ $(\mathrm{P}<0.05)$.

c Significant differences between SOY and others $(\mathrm{P}<0.05)$.

d Significant differences between SOY and $\operatorname{SOPM}(\mathrm{P}<0.05)$.

e Significant differences between PALM and $\operatorname{SOPM}(\mathrm{P}<0.05)$.

와 비교하여 유의적으로 소화율이 증가하였다 $(\mathrm{P}<0.05)$. 또한, SOPM12.5 구와 SOPM25 구는 $\mathrm{SOY}$ 구와 비교하여 통계적인 차이를 보이지 않았다 $(\mathrm{P}>0.05)$. 이는 이유자돈에 있어 대두유 의 지방산 소화율이 tallow 또는 tallow와 monoglyceride의 혼합급여와 비교하여 증가하였 다는 Jones 등(1992)의 시험과 유사한 결과를
나타내었으며, tallow와 monoglyceride의 혼합급 여는 tallow의 단일급여보다 높은 지방산 소화 율을 나타내었다고 보고하여 monoglyceride의 형태로의 지방은 자돈에 있어 높은 흡수율을 나 타내는 것으로 사료된다. 또한, Garrett와 Young (1975)은 여러 종류의 monoglyceride는 palmitic acid의 흡수를 개선한다고 보고하여 본 실험에 
서 사용된 건조분말팜유 내 지방의 소화율이 증가된 것으로 보인다. 본 시험에서 $\mathrm{DM}, \mathrm{N}$ 및 $\mathrm{DE}$ 의 소화율에 있어서는 처리구간 차이를 보이 지 않았으며(P>0.05), 이는 $\mathrm{Li}$ 등(1990)과 Jones 등(1992)의 시험과 유사한 결과를 나타내었다.

건조팜유분말의 급여가 이유자돈의 등지방 두께에 미치는 영향을 Table 5에 나타내었다. 등지방 두께는 $25 \%$ monoglyceride를 함유한 SOPM 구, PALM, 12.5\% monoglyceride를 함유 한 SOPM 구, monoglyceride를 함유하지 않은 $\mathrm{SOPM}$ 구, SOY 구 순으로 증가하였으나, 유의 적인 차이는 나타나지 않았다 $(\mathrm{P}>0.05)$.

이유자돈에 있어 건조팜유분말의 급여가 혈 청내 콜레스테롤의 변화에 미치는 영향을 Table 6에 나타내었다. SOY 구는 다른 처리구 와 비교하여 혈청 내 total cholesterol, HDLcholesterol과 total lipid 함량에 있어서는 유의적 으로 감소하였으며 $(\mathrm{P}<0.05)$, free fatty acid 함량에 있어서는 증가하였다 $(\mathrm{P}<0.05)$. 또한, triglyceride
함량에 있어서는 PALM 구가 SOPM 구와 비교 하여 증가하였다 $(\mathrm{P}=0.06)$. 이는 이유자돈에 대 두유, tallow의 단일급여, 대두유와 tallow 및 대 두유와 monoglyceride의 혼합급여시 대두유만을 급여한 자돈에 있어 혈청 내 triglyceride, total, $\mathrm{HDL}$ 및 $\mathrm{LDL}$ cholesterol의 함량이 가장 낮게 나타났다는 Jones 등(1992)의 보고와 유사하였으 며, 또한, tallow의 단일 급여는 대두유와 tallow 및 대두유와 monoglyceride의 혼합급여와 비교 하여 혈청 내 triglyceride 함량이 증가하였다는 결과와도 유사하였다(Jones 등, 1992). 이는 돼 지에 있어 일반적인 식물성 유지가 포함하는 장쇄(>C14) 불포화지방산의 급여가 일반적인 동물성 유지의 장쇄 포화지방산의 급여와 비교 하여 혈청 내 triglyceride의 농도를 감소시키는 것에 기인한 것이라 보인다(Cera 등, 1989). 본 실험의 건조팜유분말의 지방산 조성은 palmitic $\operatorname{acid}(\mathrm{C} 16: 0)$ 와 stearic $\operatorname{acid}(\mathrm{C} 18: 0)$ 와 같은 포화지 방산을 많이 함유하며, 이는 대표적 동물성 유

Table 5. Effect of dried palm oil powder on backfat thickness in weaned pigs ${ }^{\perp)}$

\begin{tabular}{|c|c|c|c|c|c|c|}
\hline \multirow{2}{*}{ Item } & \multirow{2}{*}{$\mathrm{SOY}^{2)}$} & \multirow{2}{*}{ PALM $^{2)}$} & \multicolumn{3}{|c|}{$\mathrm{SOPM}^{2)}$} & \multirow{2}{*}{$\mathrm{SE}^{3)}$} \\
\hline & & & 0 & 12.5 & 25 & \\
\hline Backfat thickness, mm & 7.75 & 7.29 & 7.54 & 7.33 & 7.17 & 0.32 \\
\hline
\end{tabular}

Table 6. Effect of dried palm oil powder on serological changes in weaned pigs ${ }^{1)}$

\begin{tabular}{|c|c|c|c|c|c|c|}
\hline \multirow{2}{*}{ Item } & \multirow{2}{*}{$\mathrm{SOY}^{2)}$} & \multirow{2}{*}{ PALM $^{2)}$} & \multicolumn{3}{|c|}{$\mathrm{SOPM}^{2)}$} & \multirow{2}{*}{$\mathrm{SE}^{3)}$} \\
\hline & & & 0 & 12.5 & 25 & \\
\hline Total cholesterol, mg/dL ${ }^{\mathrm{cd}}$ & $74.13^{\mathrm{b}}$ & $91.75^{\mathrm{a}}$ & $80.13^{\mathrm{ab}}$ & $90.63^{\mathrm{a}}$ & $86.13^{\mathrm{ab}}$ & 4.42 \\
\hline HDL-cholesterol, mg/dL ${ }^{\mathrm{cd}}$ & $25.25^{\mathrm{b}}$ & $31.25^{\mathrm{ab}}$ & $28.50^{\mathrm{ab}}$ & $33.75^{\mathrm{a}}$ & $29.25^{\mathrm{ab}}$ & 1.93 \\
\hline Triglyceride, $\mathrm{mg} / \mathrm{dL}^{\mathrm{e}}$ & $53.25^{\mathrm{b}}$ & $75.75^{\mathrm{a}}$ & $66.63^{\mathrm{ab}}$ & $60.00^{\mathrm{ab}}$ & $54.13^{\mathrm{ab}}$ & 6.86 \\
\hline Total lipid, $\mathrm{mg} / \mathrm{dL}^{\mathrm{cd}}$ & 197.88 & 230.50 & 221.50 & 236.25 & 214.13 & 12.09 \\
\hline Free fatty acid, $\mu \mathrm{Eq} / \mathrm{L}^{\mathrm{cd}}$ & $194.25^{\mathrm{a}}$ & $87.63^{\mathrm{b}}$ & $94.38^{\mathrm{ab}}$ & $100.25^{\mathrm{ab}}$ & $119.75^{\mathrm{ab}}$ & 29.87 \\
\hline
\end{tabular}

1) Blood samples were taken from ten pigs per treatment.

2) Abbreviated SOY, 5\% soybean oil; PALM, 5.5\% dried palm oil powder; SOPM, 2.5\% soybean oil and $2.7 \%$ dried palm oil powder included $0 \%, 12.5 \%$ and $25.0 \%$ monoglyceride.

3) Pooled standard error.

ab Means in the same row with different superscripts differ $(\mathrm{P}<0.05)$.

c Significant differences between SOY and others $(\mathrm{P}<0.05)$.

d Significant differences between SOY and $\operatorname{SOPM}(\mathrm{P}<0.05)$.

e Significant differences between PALM and $\operatorname{SOPM}(\mathrm{P}=0.06)$. 
지인 tallow 또는 lard의 조성과 매우 비슷하다. 혈청 내 free fatty acid는 혈중 지질 내 $2 \%$ 이 하로 함유되어 있으며, 이들은 주로 지방산 C16:0, C18:2, C18:3로 이루어져 있다. 또한, free fatty acid는 지방조직의 triglyceride가 분해되어 혈액 내 저장되어, 체내에서 근육 등으로 이동 해 에너지원으로 사용된다.

일반적으로 가축에 있어 지방의 이용성은 포 화 지방산보다 불포화지방산에서 높게 나타나 는 것으로 알려져 있으며(Cera 등, 1989; Li 등, 1990), 포화지방산의 급여는 혈액 내 콜레스테 롤농도 상승효과를 갖는 것으로 보고되고 있다 (Peifer 등, 1960; Ramesha 등, 1980) 본 실험에 서도 대두유의 급여는 건조분말팜유의 단일 급 여보다 높은 지방 소화율을 나타내었으며, 혈 청 콜레스테롤 및 triglyceride 함량에 있어서도 감소하는 것으로 나타났다. 또한, monoglyceride 가 함유된 건조팜유분말은 건조팜유분말만을 급여한 처리구와 비교하여 지방 소화율을 개선 하는 효과를 나타내었으며, 이는 monoglyceride 형태로의 지방이 이유자돈에 있어 흡수율을 개 선시키는 작용에 의한 것으로 사료된다.

\section{IV. 요 약}

본 실험은 이유자돈에 있어 대두유, 건조팜 유분말과 monoglyceride의 첨가가 성장 및 혈청 내 콜레스테롤 변화에 미치는 영향을 조사하기 위하여 실시하였다. 3 원 교잡종 $[(\mathrm{Y} \times \mathrm{L}) \times \mathrm{D}]$ 자 돈 125 두(개시시 체중 $6.00 \pm 0.79 \mathrm{~kg}$ )를 공시하 여 21일간 사양시험을 실시하였다. 시험설계는 기초사료 내 일반대두유 $5 \%$ 를 함유한 처리구 (SOY), 건조팜유분말 $5.5 \%$ 를 함유한 처리구 (PALM), 일반대두유 $2.5 \%$ 와 $0 \%, 12.5 \%, 25 \%$ 의 monoglyceride를 각각 첨가한 건조팜유분말 $2.7 \%$ 를 함유한 처리구(SOPM0, SOPM12.5, SOPM25) 의 5 개 처리를 두었다. $0-21$ 일간의 총 사양시 험기간동안, 일당사료섭취량은 monoglyceride를 함유한 SOPM 구와 PALM 구가 SOY 구, monoglyceride를 함유하지 않은 SOPM 구와 비 교하여 증가하였다 $(\mathrm{P}<0.05)$. 일당증체량 및 사 료효율에 있어서는 처리구간 차이를 보이지 않
았다. 지방소화율에 있어서는 SOY 구가 가장 높았으며 $(\mathrm{P}<0.05)$, monoglyceride를 함유한 SOPM 구는 PALM 구와 비교하여 유의적으로 소화율 이 증가하였다 $(\mathrm{P}<0.05)$. SOPM12.5 구와 SOPM25 구는 $\mathrm{SOY}$ 구와 비교하여 통계적인 차이를 보 이지 않았다 $(\mathrm{P}>0.05)$. 그러나, $\mathrm{DM}, \mathrm{N}$ 및 $\mathrm{DE}$ 의 소화율에 있어서는 처리구간 차이를 보이지 않 았다 $(\mathrm{P}>0.05)$. 등지방 두께는 처리구간 유의적 인 차이를 나타내지 않았다 $(\mathrm{P}>0.05)$. 혈청 내 콜레스테롤 농도에 있어서는 SOY 구는 다른 처 리구와 비교하여 혈청 내 total cholesterol, HDLcholesterol과 total lipid 함량에 있어서는 유의적으 로 감소하였으며 $(\mathrm{P}<0.05)$, free fatty acid 함량에 있어서는 증가하였다 $(\mathrm{P}<0.05)$. 또한, triglyceride 함량에 있어서는 PALM 구가 SOPM 구와 비교 하여 증가하였다 $(\mathrm{P}=0.06)$. 결론적으로, 이유자돈 에 있어 대두유의 급여는 건조팜유분말의 단일 급여보다 높은 지방 소화율을 나타내었으며, 혈 청 콜레스테롤 및 triglyceride 함량에 있어서도 감소하는 것으로 나타났다. 또한, monoglyceride 가 함유된 건조팜유분말은 건조팜유분말만을 급여한 처리구와 비교하여 이유자돈의 지방 소 화율을 개선하는 효과를 가지는 것으로 사료된 다.

(색인: 건조팜유분말, 모노글리세라이드, 성장 율, 혈청 지질, 이유자돈)

\section{$\mathrm{V}$. 인 용 문 헌}

1. AOAC. 1995. Official method of analysis. 16th Edition. Association of Official Analytical Chemists, Washington, DC.

2. Cera, K. R., Mahan, D. C. and Reinhart, G. A. 1989. Apparent fat digestibilities and performance responses of postweaning swine fed diets supplemented with coconut oil, corn oil or tallow. J. Anim. Sci. 67:2040-2047.

3. Clerc, M. 1992. Bulletin de Academic Nationale de Medicine. 176:1393-1410.

4. Crampton, E. W. and Ness, O. M. 1954. A meal mixture suitable as the entire ration to be self-fed dry to pigs weaned at ten days of age. J. Anim. 
Sci. 13:357.

5. Duncan, D. B. 1955. Multiple range and multiple F tests. Biometrics. 11:1.

6. Fanimo, A. O. and Fashina-bombata, H. A. 1998. The response of weaner pigs to diets containing palm oil slurry. Anim. Feed. Sci. Tech. 71:191195.

7. Frobish, L. T., Hays, V. M., Speer, V. C. and Ewan, R. C. 1970. Effect of fat source and level on utilization of fat by young pigs. J. Anim. Sci. 30:197.

8. Gapor, A. B., Ong, A. S. H., Kato, A., Watanabe, H. and Kawada, T. 1989. Antioxidant activities of palm vitamin $\mathrm{E}$ with special reference to tocotrienols. Elaies, The Int. J. Oil. Palm. Res. Dev. 1:63-67.

9. Garrett, R. L. and Young, R. J. 1975. Effect of micelle formation in the absorption of neutral fat and fatty acids by the chicken. J. Nutrition. 105: 827.

10. Jin, Y. H. 1997. Effects of consuming diets incorporating soybean oil, canola oil and palm oil on serum lipids and fecal fat excretion in humans. Korean. J. Nutrition. 30:1073-1083.

11. Jones, D. B., Hancock, J. D., Harmon, D. L. and Walker, C. E. 1992. Effects of exogenous emulsifiers and fat sources on nutrient digestibility, serum lipids and growth performance in weanling pigs. J. Anim. Sci. 70:3473-3482.

12. Lawrence, N. J. and Maxwell, C. V. 1983. Effect of dietary fat sources and level on the performance of neonatal and early weaned pigs. J. Anim. Sci. 57:936.
13. Lawrence, N. J., Maxwell, C. V. and Belcher, C. G. 1980. Okla. State Univ. Anim. Sci. Res. Rep. MP-107, USA. p.159.

14. Li, D. F., Thaler, R. C., Nelssen, J. L., Harmon, D. L., Allee, G. L. and Weeden, T. L. 1990. Effect of fat sources and combinations on starter pig performance, nutrient digestibility and intestinal morphology. J. Anim. Sci. 68:3694-3704.

15. Mattson, F. H. and Beck, L. W. 1956. The specificity of pancreatic lipase for the primary hydroxyl groups of glycerides. J. Biol. Chem. 219:735.

16. NRC. 1998. Nutrient requirement of pigs(10th Ed.) National Research Council, Academy Press. Washington, D. C.

17. Panja, P., Kassim, H. and Jalaludin, S. 1995. Effects of palm oil and soybean oil as fat sources in isonitrogenous and isocalrolic diets on the performance of broilers. Asian-Aust. J. Anim. Sci. 16:1035-1040.

18. Peifer, J. J., Janssen, F., Ahn, P., Cox, W. and Lundberg, W. O. 1960. Studies on the distribution of lipids in hypercholesterolemic rats. Arch. Biochem. Biophys. 86:302.

19. Ramesha, C. S., Paul, R. and Ganguly, J. 1980. Effect of dietary unsaturated oils on the biosynthesis of cholesterol and on biliary and fecal excretion of cholesterol and bile acids in rats. J. Nutr. 110:2149.

20. SAS. 1996. SAS user's guide. Release 6.12 edition. SAS Institute. Inc., Cary, NC.

(접수일자 : 2005. 11. 17. / 채택일자 : 2006. 3. 7.) 